\title{
Nolasco, Margarita, Marina Alonso et al., (coords.) 2009, "Chiapas, el archivo y la etnografía”, en Los pueblos indígenas de Chiapas. Atlas etnográfico, Coordinación de Antropología, Instituto Nacional de Antropología e Historia, pp. 490.
}

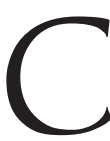

on la dolorosa ausencia de Margarita Nolasco, la coordinación de antropología del INAH publica ahora este volumen del cual ella también es coautora y coordinadora, y que recoge muchas horas y años de trabajo de archivo e investigación de campo de historiadores, antropólogos y otros especialistas. Se presentan en apretada síntesis descripciones, explicaciones, preguntas y pautas de investigación sobre la vida y la cultura de los pueblos indígenas chiapanecos y mesoamericanos. ${ }^{1}$ A diferencia del atlas usual que es más bien compilación de mapas, este trabajo colectivo asume la investigación históricoetnográfica simultáneamente como construcción del dato cultural, como texto y como placer de la lectura. Se ofrecen panoramas condensados de la realidad chiapaneca, priorizando el problema de dilucidar los mecanismos de explotación de los indígenas, la fuerza de sus tradiciones primordiales y su capacidad política para construir nuevos espacios de diálogo e interlocución con el Estado mexicano.

Dada la resonancia internacional y nacional que Chiapas ganó por la manera en que llegó al fin del milenio y entró al siglo veintiuno, uno esperaría encontrar en un atlas de este tipo informaciones y cuestionamientos que ayuden a entender cómo llegamos a la situación presente y cuáles pudieran ser —o en la práctica son- las rutas a través de las cuales Chiapas puede acceder a una modernidad más democrática, con dignidad, igualdad y justicia reclamadas desde tiempos ancestrales por los pueblos indígenas y mestizos. Tras una lectura crítica puede decirse que, gracias a la calidad de los trabajos escritos por los más de 30 especialistas convocados y el cuidado de los editores, este Atlas logra exitosamente ofrecer una sólida perspectiva de la historia, la cultura, la economía y la sociedad del estado. Cada pieza sintetiza muchas lecturas, viajes y trabajos de campo, que realzan la singularidad del dato concreto, mucho más convincente que cualquiera de las más sesudas generalizaciones. Además, se ofrece una batería de mapas y cuadros y un espléndido soporte de más de 400 fotografías que por sí mismos constituyen un valioso insumo, así como un excelente instrumento de trabajo al alcance del lector no especializado.

Este Atlas toma posición a favor de la etnografía y el archivo y critica la idea de los pueblos indígenas como espacios corporados y cerrados, ajenos a la división internacional del trabajo y a las tensiones entre tradición y modernidad, rara vez incluidas en las etnografías clásicas, que crearon la representación de las comunidades como los llamados espacios prístinos, desvinculados de los procesos locales, nacionales y globales. 
El Atlas sale bien librado de la folklorización de la cultura, aborda los conflictos, ambigüedades y contradicciones, suprimidos por la visión exotista de cierta academia defensora tutelar de lo indígena, que sataniza a la sociedad mestiza y cultiva el puritanismo étnico y la re-racialización de nuestras sociedades. Este Atlas contiene además elementos empíricos para situar la relación geopolítica del Sureste mexicano con Centroamérica desde una perspectiva indígena, crítica del centralismo y útil para visualizar el desarrollo de los Estudios Centroamericanos y Mesoamericanos, una iniciativa liderada desde hace varios años en Chiapas por Andrés Fábregas Puig y Jesús Morales Bermúdez, quienes han sido firmesimpulsores de la necesidad de aprender de las experiencias centroamericanas, de sus aciertos y virtudes, pero principalmente, del error de apostarle todo a la ley del instinto y a la militarización de la sociedad, el Estado y el territorio.

De manera sistemática y organizada los autores abordan la historia y la situación de los pueblos y las lenguas indígenas, el mundo ceremonial, las dinámicas de conversión religiosa, incluidas las de los sufís y los sunnis chamulas, caracterizados en la excelente contribución de Gaspar Morquecho. Según la doctora Nolasco, en el atlas se trata de mostrar la historia de los indios chiapanecos que siempre han sido rebeldes, la complejidad política de sus nuevas instancias organizativas y la "enorme diversidad" de Chiapas en "un solo espacio civilizatorio". Destacan las contribuciones de Juan Pedro Viqueira sobre las familias lingüísticas, la multietnicidad prehispánica, la reciente expansión territorial de los grupos mayenses y la reindianización de las Montañas Mayas en proceso. Hadlyyn Quadriello hace una rápida y utilísima caracterización de las regiones fisiográficas, económicas y culturales de Chiapas. En poco espacio, Mario H. Ruz explica en sus indiofanías chiapanecas la congregación, reducción y ladinización de los pueblos autóctonos, los vínculos entre los indios de Chiapas y Tabasco, la continua movilidad propia de la vida cotidiana indígena, las exacciones y las maneras de generar excedentes para sostener a los nuevos señores, a los artesanos y sirvientes domésticos; la iconografía católica y las deidades indígenas; la caza, la pesca, la tecnología, la flora y sus usos, así como la forma de construir las casas y el arsenal terapéutico. Además, el autor se concentra enlas maneras que tienen los indígenas de adornarse el cuerpo, la vida de los artesanos prehispánicos y lo que define como etnografía del gozo ritual, las comedias jocosas $y$, en general, las expresiones festivas prehispánicas y coloniales. Jan de Vos, por su parte, revisita en su estudio la división administrativa y sociocultural en el Soconusco y la Alcaldía mayor de Chiapa, al tiempo que pone de relieve el poder económico de los dominicos y recuerda la historia de Hernán Cortés que, impresionado por el lucrativo cultivo de cacao en el Soconusco, declara la provincia entera como su encomienda personal.

Sonia Toledo, Rodrigo Megchún y Haddlynn Quadriello abordan el finquerismo en Chiapas, la estructura agraria, la ganaderización como el principal elemento en que se asienta la estratificación social entre los indígenas y la definición de la finca como un complejo sociohistórico, jurídicamente normado, socialmente legitimado, económicamente operante y culturalmente significado. Quadriello, por ejemplo, analiza la finca como espacio donde los indios reproducen su propia etnicidad durante el siglo XIX, su liberación de la finca gracias al cardenismo, el reparto agrario y las mejoras en la escuela, la salud y las comunicaciones. Se caracterizan asimismo los jalones de la evangelización indígena a partir de 1974 y el fenómeno de los indios nuevos de los años noventa con una mentalidad más combativa y mayor escolaridad, todo con el telón de fondo de la pobreza, que actualmente obliga a una familia de seis personas a vivir con menos de 40 pesos diarios. Esta situación dibuja un etnopaisaje chiapaneco en el cual 96.5\% de los municipios indígenas están catalogados como de muy alta y alta marginación. Ello sin embargo, escribe Nolasco, no impide que prospere el deseo por 
ser libres, modernos e iguales, a la par de la tradición indocolonial del cabildo indígena basado en el medieval español, y la organización de la estructura política de los barrios y la costumbre de vivir en parajes, articulada en torno al cuidado de la iglesia, la enseñanza de la doctrina y la fiesta de los santos, especialmente la del santo patrono.

Como parte de esta relación entre los santos y las formas de gobierno indígena, Marina Alonso explora las cosmovisiones, la relación entre la memoria de la experiencia agrícola y el cómputo del tiempo, la importancia del saber contar los días, la tradición oral y la geografía sagrada, en la que sobresalen los ojos de agua, las cuevas, las barrancas, y en general todas las entradas al inframundo vinculadas al mundo de los sueños; el curarse, saber predecir el futuro, el culto a los santos, la identificación entre éstos y las deidades prehispánicas, y la ética de convivencia social contenida en el saber popular indígena. Con fluidez analítica y amenidad etnográfica, Alonso examina la música como reveladora de la interculturalidad entre lo que se asume como propio y lo ajeno, así como el papel de la herbolaria, los masajes y los frotamientos para propiciar el equilibrio del hombre con la naturaleza, con las deidades, con el otro mundo y consigo mismo. También, en el texto se examina la relación entre gobierno y familia a partir de temas clásicos como el matrimonio, la procreación y la vida en pareja, que arranca a los 13 ó 14 años con el acostumbrado "robo de la novia", y contribuye a la reproducción de familias patrilineales y patrilaterales, articuladas de diversas maneras con el sistema de cargos y las jerarquías cívico religiosas, que propagan el culto a los santos y operan como un sistema de control social.

En cuanto a esta relación entre el santo patrón titular y el cambio de autoridades, Margarita Nolasco destaca a la selva como la región más tolerante y señala las varias formas de catolicismo indígena que a lo largo del año se practican en un apretado calendario ritual que permite la permanencia de ideas, creencias, mitos y ritos de origen prehispánico. En la dimensión de la interacción entre cosmovisiones, poder, violencia, modernidad y Estado, Hadlynn Quadriello revisa la poca participación de la Iglesia católica en Chiapas durante un dilatado período que va de 1859 a 1944: las posturas del anticlericalismo liberal chiapaneco, que veía a los sacerdotes como vagos y malvivientes, clasificables en el mismo rango de las prostitutas; $y$, posteriormente, los giros eclesiásticos hacia la opción preferencial por los pobres y el surgimiento de la teología india de la liberación. En otro ámbito etnográfico, la autora destaca el papel de las romerías tojolabales y los sistemas normativos para el manejo de los conflictos, la brujería y los casos de envidia. Entre la religión y las tensiones entre la reproducción cultural, la tradición y la modernidad, Carolina Rivera Farfán desarrolla en su artículo una historia breve del pentecostalismo en Chiapas. Por su parte, Gracia Imberton analiza temas poco trabajados como la enfermedad de la vergüenza entre los choles que, afirma la autora, es expresión de tensiones sociales en los marcos de una sociedad desigual que compite por recursos escasos y preciados en condiciones de extrema precariedad. En situación similar, en cuanto a las escasas investigaciones sobre el tema, Anna Garza Caligaris estudia las relaciones de género entre los tzotziles de San Pedro Chenalhó y la participación y distintos posicionamientos de las mujeres en la economía y el zapatismo.

En la línea de análisis de los sistemas de cargos de las sociedades tzeltales, así como los conservadurismos tradicionalistas entremezclados con el acto devocional, las inercias autoritarias y el faccionalismo y poder caciquil, Pedro Pitarch publica una interpretación de la rebelión de ese grupo étnico de 1712, en la voz de uno de sus informantes de San Juan Cancuc. Por su parte, entre todas las voces y plumas que aparecen contando su historia, Cristina Gómez presenta una autoetnografía-testimonio. Miguel Hernández Díaz analiza desde una perspectiva filosófica las ideas de Dios 
según los tzotziles e ilustra la perspectiva indígena del mundo sobre el aprender a trabajar como el kaxlán, más relajado, dándole gusto al cuerpo y, en lugar de estar con el sol encima todo el día, cultivar el pensamiento rompiendo el estereotipo que aleja a los indígenas del ámbito de la educación, la movilidad social y los códigos de la modernidad que, a lo largo de la historia, han sido apropiados y reelaborados por ellos, como pareciera comprobarse en otro ensayo en donde Hernández Díaz evalúa los aportes de la literatura indígena.

Hay que señalar que este atlas reitera el parentesco desde tiempo inmemorial entre los indios mexicanos y los pueblos centroamericanos, que, aún en el presente, vinculados por la cercanía material y simbólica, tienden a imaginar a Chiapas como el más centroamericano de los estados del Sureste mexicano. En esa tónica, Marina Alonso hace una recensión de la migración y la trashumancia indígena de "los que se fueron a El Nacional", así como de la experiencia del refugio guatemalteco en México, la reorganización comunitaria, la integración, el retorno voluntario y los matrimonios mixtos. En el mismo contexto Megchún aborda el tema de los desplazamientos forzosos y el desmantelamiento de los municipios autónomos. Valga recordar, asimismo, que Margarita Nolasco fue muy activa en las investigaciones sobre los refugiados guatemaltecos en los años ochenta del siglo pasado, y una prominente propulsora de una visión transfronteriza, cuya necesidad se hizo más evidente a partir del levantamiento zapatista de 1994.

A propósito de este levantamiento y de las dinámicas del poder indígena, Araceli Burguete desarrolla una perspectiva contemporánea sobre el ayuntamiento indígena, los sistemas de cargos, los municipios zapatistas rebeldes y las instancias múltiples y heterogéneas del poder político en donde se resuelven cuestiones como la normatividad y la autonomía. Ya en el ámbito estricto del zapatismo, Rodrigo Megchún propone ver en éste un movimiento con estrategia política premeditada con pretensiones de alcance nacional, que apuesta a la construcción de un contrapoder social y a nuevas formas de ciudadanía. Un movimiento si bien excluyente, al pretender asumir la dirección de algunos encuentros, pero que tanto en su carácter nacional e indígena, como en su condición de ejército de autodefensa con capacidad de construir símbolos aglutinantes, pelea por la inserción igualitaria y la dignificación del colectivo. Las posiciones de Megchún contrastan con las de Xóchitl Leyva, que asegura que en México no se trata de una guerrilla zapatista al estilo de las latinoamericanas que pugnaron por el concepto de guerra de guerrillas populares, sino de un neozapatismo formado por procesos de convergencia, flujos y movilizaciones de tipo guevaristas y no marxistaleninistas, basado en redes transnacionales de defensoría indígena y social, que promueven un nuevo marco de discusión con el Estado.

Aquí, a propósito de todas esas posturas, cabrían las siguientes preguntas: si este neozapatismo es un mero movimiento antisistémico, ¿dónde tendría que insertarse el análisis del desarrollismo contrainsurgente a la mexicana y la ocupación de Chiapas por parte del Ejército Federal? ¿Qué tan cierto es que las guerrillas latinoamericanas no desarrollaron redes políticas y de abastecimiento similares a las del zapatismo moderno mexicano? ¿Cuál es la relación entre el altermundismo hacia fuera y la relación del carácter indígena de este zapatismo y su arraigo local con el pobrerío mestizo? ¿Cuáles pueden ser, a su vez, los términos de la reconversión productiva de la economía de plantación en venta de naturaleza y cultura?, y, por último, icuál sería la durabilidad de una autonomía política sin acceso a dinero público?

Margarita Nolasco escribe que el EZLN hizo que la cuestión indígena pasara de ser un problema de educación a uno de seguridad nacional. Considera además que la notable influencia de los zapatistas chiapanecos sobre la lucha política de los yaquis, ayudó a refuncionalizar los símbolos e introducir 
novedades en la metamorfosis del faccionalismo y el caciquismo, ahora en un contexto militarizado. Se le ha atribuido al EZLN ser una guerrilla altermundista, autonómica, de carácter regional que apunta a la construcción de un nuevo sujeto intercultural y una ciudadanía post-capitalista. Cabe esperar que en este sentido no prive algún principio de diferenciación étnica para mejor gobernar, sino la visión de una nueva sociedad posterior a la declinación del dogma neoliberal y las formas más extremas del darwinismo social, caracterizadas por exaltar la ley del más fuerte y los principios de la selección natural. Si el punto de llegada de las agendas democráticas es el individualismo radical clásico de las democracias postindustriales, no queda claro si la apuesta por nuevas diferenciaciones puede resultar en formas alternativas de ciudadanía, o si las demandas teóricas y operativas para pensar y construir una ciudadanía post-capitalista con sus propios repertorios y anti-valores, puedan estar mucho más cercanos al ser primordial de lo indígena, que lo que los culturalistas anti-ladinos están dispuestos a reconocer. Igualmente, queda la duda de si la preeminencia de derechos colectivos fortaleciendo los derechos individuales, permite pensar en una ciudadanía post-capitalista no etnitizada, que frene la voracidad de los intereses privados y restituya la función social de la propiedad y la obligación del Estado de promover el bien común.

Este Atlas trata temas de difícil interpretación irreductibles a respuestas únicas o totalizadoras, incluidos aquellosvinculados al respeto a los derechos, la dignidad, la autodeterminación, el territorio o la justicia propia, como lo permite ver el análisis deMarisol Melesio, quien se ocupa de la ineficacia de los sistemas judiciales, el uso de militares en funciones policíacas, la impunidad selectiva de responsables de violaciones de derechos humanos, la tolerancia a grupos armados antizapatistas, las desapariciones forzosas que provocan desplazamientos, y la distorsión por la pobreza en Chiapas.

A propósito del levantamiento zapatista, se señala por ejemplo que poco se ha dicho sobre la manera en que la Iglesia católica supo proveer en Chiapas espacios de concurrencia popular organizada, allí donde el Estado y el resto de la sociedad fueron incapaces de crearlos. Queda por evaluar el resultado de estos experimentos políticos y organizativos, y las consecuencias de aplicar en Chiapas, como antes en Guatemala, la "ley del instinto" al momento de las movilizaciones populares, así como la praxis del acto político como acto de fe y obediencia, y no como acto civil y laico de información y conocimiento. Ello no implica ignorar el fortalecimiento de otros canales para expandir la denominada conciencia o concientización, y el fomento de actitudes y valores de solidaridad y beneficio colectivo, como es el caso de los nuevos indios de los noventa a los que se refiere Margarita Nolasco en el volumen.

Ojalá y una futura edición de este atlas incluya más sobre el papel de Chiapas como expulsor de mano de obra y zona de reconversión de la economía de plantación en venta de naturaleza y cultura, así como territorio de viajeros en tránsito, turistas, migrantes y trabajadores indocumentados, que juntos participan de la diáspora mesoamericana que se extiende por México y Estados Unidos, y que ha producido configuraciones neobarrocas, transnacionales y post-nacionales, imposibles de aprehender con los análisis usuales, demasiado circulares, localistas, y repetitivos.

En estos tiempos de declinación civilizatoria y muerte cultural, no es cosa menor que la coordinación de antropología del INAH persevere en el esfuerzo por revitalizar la etnografía de las regiones indígenas de México, y proponga estrategias para hacerla más plural, polifónica, multivocal, y dialógica. 
Notas

${ }^{1}$ A propósito de Los pueblos indígenas de Chiapas. Atlas etnográfico. Margarita Nolasco y Marina Alonso, Hadlyyn Cuadriello, Rodrigo Megchún, Miguel Hernández y Ana Laura Pacheco (coords.). Agradezco a Marina Alonso Bolaños y Gloria Artís Mercadet la invitación a leer y comentar este atlas con tantas novedades para el conocimiento de la rica herencia de los pueblos indígenas chiapanecos.

\section{Dr. Jorge Ramón González Ponciano}

Centro de Estudios Mayas

Instituto de Investigaciones Filológicas

Universidad Nacional Autónoma de México. 